\title{
Erratum to: 'CompGO: an R package for comparing and visualizing Gene Ontology enrichment differences between DNA binding experiments'
}

Ashley J. Waardenberg ${ }^{1,2^{*}}$, Samuel D. Bassett ${ }^{1}$, Romaric Bouveret ${ }^{1,3}$ and Richard P. Harvey ${ }^{1,3,4,5}$

Unfortunately, the original version of this article [1] contained an error. The author's family name was spelt incorrectly as 'Basset'. We have included it here correctly as 'Bassett' for reference. The original article will be corrected to reflect this.

\begin{abstract}
Author details
'Victor Chang Cardiac Research Institute, Darlinghurst, NSW 2010, Australia. ${ }^{2}$ Present Address: Children's Medical Research Institute, Westmead, NSW 2145, Australia. ${ }^{3}$ St. Vincent's Clinical School, University of New South Wales, Kensington 2052, Australia. ${ }^{4}$ School of Biotechnology and Biomolecular Sciences, University of New South Wales Faculty of Science, New South Wales 2052, Australia. ${ }^{5}$ Stem Cells Australia, Melbourne Brain Centre, University of Melbourne, Victoria 3010, Australia.
\end{abstract}

Received: 30 March 2016 Accepted: 30 March 2016

Published online: 25 April 2016

\section{Reference}

1. Waardenberg AJ, Bassett SD, Bouveret R, Harvey RP. CompGO: an R package

for comparing and visualizing Gene Ontology enrichment differences between DNA binding experiments. BMC Bioinformatics. 2015;16:275.

\footnotetext{
* Correspondence: awaardenberg@cmri.org.au

'Victor Chang Cardiac Research Institute, Darlinghurst, NSW 2010, Australia 2Present Address: Children's Medical Research Institute, Westmead, NSW 2145, Australia
}

Submit your next manuscript to BioMed Central and we will help you at every step:

- We accept pre-submission inquiries

- Our selector tool helps you to find the most relevant journal

- We provide round the clock customer support

- Convenient online submission

- Thorough peer review

- Inclusion in PubMed and all major indexing services

- Maximum visibility for your research

Submit your manuscript at www.biomedcentral.com/submit 西 